\title{
Tailgut Cyst, Report of 24 Cases Single Center Experience
}

\author{
Han Deok Kwak ${ }^{1}$, Chang Hyun Kim² \\ ${ }^{1}$ Department of Surgery, Chonnam National University Hospital, Gwangju; ${ }^{2}$ Department of Surgery, Chonnam National University Hwasun \\ Hospital, Hwasun, Korea
}

\section{See Articles on Page 268-274}

Retrorectal tumor was first described in a case report in 1885 [1] and, according to the Mayo Clinic, is very rare, with a frequency of 1 in 40,000 patients [2]. The United States Armed Forces Institute of Pathology has published 53 cases over 35 years, showing that the condition is predominant in females and causes inflammation in half of the patient population. Biopsies in most patients have confirmed remnants of the embryonic tailgut [3]. This tumor can be malignant and then requires preoperative evaluation or surgery. Another study that published 34 cases over 22 years reported a higher probability of malignancy in male patients, patients who had painful symptoms, and patients of advanced age [4].

Sakr et al. [5] analyzed 24 patients who underwent surgery over 12 years; to the best of our knowledge, this is the first Korean case series. Similar to others, this study found that tumor occurrence was predominant in females, and that asymptomatic patients accounted for more than half of the total. The differences from previous studies were that tumor location was analyzed relative to the levator muscle, and that surgical approaches were classified as anterior with laparoscopy, posterior through the perineum, or a combined approach. Following this classification, the authors found the highest complication rate $(\mathrm{P}=0.021)$ in the posterior group, and that a larger tumor size $(\mathrm{P}=0.001)$ and more tumors located above the coccyx $(P=0.002)$ resulted in a higher rate of the combined approach.

It is also noteworthy that 10 cases were laparoscopically resected, indicating a recent trend of laparoscopic abdominal surgery. Lap-

Correspondence to: Chang Hyun Kim, M.D.

Department of Surgery, Chonnam National University Hwasun Hospital, Chonnam National University College of Medicine, 322 Seoyang-ro, Hwasun-eup, Hwasun 58128, Korea

Tel: +82-61-379-7646, Fax: +82-61-379-7661

E-mail: cksantiago8@gmail.com

ORCID code: https://orcid.org/0000-0002-1954-189X

(C) 2019 The Korean Society of Coloproctology

This is an open-access article distributed under the terms of the Creative Commons Attribution NonCommercial License (http://creativecommons.org/licenses/by-nc/4.0) which permits unrestricted noncommercial use, distribution, and reproduction in any medium, provided the original work is properly cited. aroscopic excision of perirectal tumors approximately $4 \mathrm{~cm}$ in diameter was first reported in Korea in 2011 at the S4 level [6]; more recently, larger-sized excision at lower levels has also been introduced [7]. As noted in this study, in cases of the anterior approach using laparoscopy, nerve damage could cause sexual dysfunction and pelvic dyssynergia. Based on the author's experience, in cases of anterior laparoscopic approach, camera access is difficult due to a narrow pelvis during distal marginal ligation of the tumor. As a result, the structure around the pelvic floor is not clearly identified, which may result in injury to the pelvic muscle or the cyst itself. On the other hand, in cases of posterior perineal resection, damage to the anal sphincter is possible and demarcation of the cyst can be difficult because the proximal margin of the tumor is not identified. In such cases, as in this study, it is believed that the combined approach can compensate for the disadvantages of each approach.

When deciding on a surgical approach in perirectal tumor resection, the operator should always consider the possibility of damage to the ureter, adjacent nerves, and neighboring organs. En bloc resection without damage to the cyst during surgery should be performed with adequate preoperative assessment, even though the rate of malignancy is low $[8,9]$.

\section{CONFLICT OF INTEREST}

No potential conflicts of interest relevant to this article were reported.

\section{REFERENCES}

1. Caropreso PR, Wengert PA Jr, Milford HE. Tailgut cyst--a rare retrorectal tumor: report of a case and review. Dis Colon Rectum 1975;18:597-600.

2. Jao SW, Beart RW Jr, Spencer RJ, Reiman HM, Ilstrup DM. Retrorectal tumors. Mayo Clinic experience, 1960-1979. Dis Colon Rectum 1985;28:644-52.

3. Hjermstad BM, Helwig EB. Tailgut cysts. Report of 53 cases. Am J Clin Pathol 1988;89:139-47.

4. Glasgow SC, Birnbaum EH, Lowney JK, Fleshman JW, Kodner IJ, Mutch DG, et al. Retrorectal tumors: a diagnostic and therapeutic 


\section{Coloproctology Han Deok Kwak and Chang Hyun Kim}

challenge. Dis Colon Rectum 2005;48:1581-7.

5. Sakr A, Kim HS, Han YD, Cho MS, Hur H, Min BS, et al. Singlecenter experience of 24 cases of tailgut cyst. Ann Coloproctol 2019; 35:268-74.

6. Lim SW, Huh JW, Kim YJ, Kim HR. Laparoscopy-assisted resection of tailgut cysts: report of a case. Case Rep Gastroenterol 2011; 5:22-7.

7. Kim CW, Lee SH. Laparoscopic resection of presacral tumor: a new approach in the era of the minimally invasive surgery. J Minim Invasive Surg 2019;22:131-3.

8. Mathis KL, Dozois EJ, Grewal MS, Metzger P, Larson DW, Devine RM. Malignant risk and surgical outcomes of presacral tailgut cysts. Br J Surg 2010;97:575-9.

9. Patsouras D, Pawa N, Osmani H, Phillips RK. Management of tailgut cysts in a tertiary referral centre: a 10-year experience. Colorectal Dis 2015;17:724-9. 